\title{
Minimally invasive radical nephrectomy: a contemporary review
}

\author{
Akbar N. Ashrafi ${ }^{1,2,3}$, Inderbir S. Gill ${ }^{1}$ \\ ${ }^{1}$ USC Institute of Urology and Catherine \& Joseph Aresty Department of Urology, Keck School of Medicine, University of Southern California, Los \\ Angeles, California, USA; ${ }^{2}$ Division of Surgery, North Adelaide Local Health Network, SA Health, Adelaide, South Australia, Australia; ${ }^{3}$ Adelaide \\ Medical School, The University of Adelaide, Adelaide, South Australia, Australia \\ Contributions: (I) Conception and design: All authors; (II) Administrative support: All authors; (III) Provision of study material or patients: All authors; \\ (IV) Collection and assembly of data: All authors; (V) Data analysis and interpretation: All authors; (VI) Manuscript writing: All authors. All authors; \\ (VII) Final approval of manuscript: All authors. \\ Correspondence to: Inderbir S. Gill. USC Institute of Urology, Keck School of Medicine, University of Southern California, 1441 Eastlake Ave, Suite \\ 7416, Los Angeles, California 90089, USA. Email: igill@med.usc.edu.
}

\begin{abstract}
Minimally invasive renal surgery has revolutionized the surgical management of renal cancer since the initial report of laparoscopic nephrectomy in 1991. Laparoscopic nephrectomy became the mainstay of management in surgically resectable renal masses since the 1990s. The growing body of literature supporting nephron-sparing surgery over the last two decades has meant that minimally invasive radical nephrectomy (MI-RN) is now the preferred treatment for renal tumors not amenable to partial nephrectomy. While there is a well-described experience with complex radical nephrectomy using standard laparoscopy, robot-assisted surgery has shortened the learning curve and facilitated greater uptake of minimally invasive surgery in difficult surgical scenarios traditionally performed open surgically. Increased experience and expertise with robot-assisted renal surgery has led to expansion of the indications for MI$\mathrm{RN}$ to include larger masses, locally advanced renal masses invading adjacent tissues or regional hilar/ retroperitoneal lymph nodes, cytoreductive nephrectomy $(\mathrm{CN})$ in metastatic disease, and concurrent venous tumor thrombectomy for renal vein or inferior vena cava (IVC) involvement. In this article, we review the various surgical techniques and adjunctive procedures associated with MI-RN.
\end{abstract}

Keywords: Laparoscopic; minimally invasive (MI); radical nephrectomy (RN); robot-assisted; robotic

Submitted Jan 15, 2020. Accepted for publication Aug 05, 2020.

doi: 10.21037/tau-2019-suc-16

View this article at: http://dx.doi.org/10.21037/tau-2019-suc-16

\section{Introduction}

Renal cancer is twice as common in men than in women and is amongst the 10 most commonly diagnosed cancers in both sexes (1). It is estimated that there will be over 73,000 cases diagnosed and almost 15,000 deaths from renal cancer in the United States in 2020 (1). Surgical resection with radical nephrectomy has been the mainstay of treatment for localized renal cell carcinoma (RCC) since open radical nephrectomy (ORN) was first described in the 1960s $(2,3)$. The first report of laparoscopic radical nephrectomy (LRN) for a small renal mass was published in 1991 (4). Initially, there was widespread acceptance of LRN as the standard of care for radical nephrectomy. More recently, the robotic- assisted laparoscopic surgery has become the standard of care in many centers, as it overcomes many of the technical and ergonomic challenges associated with pure laparoscopy. Further, the robotic platform has allowed more technically difficult procedures to be performed in a minimally invasive manner including those traditionally performed open surgically. The widespread uptake of minimally invasive approaches combined with ongoing evolution and refinement of surgical technique have resulted in significant improvements in peri-operative outcomes over the last three decades. In this article, we provide a descriptive review of the contemporary literature on minimally invasive radical nephrectomy (MI-RN). 


\section{Contemporary indications for radical nephrectomy}

Traditionally, radical nephrectomy involves removal of the entire kidney with the surrounding Gerota's fascia incorporating the perinephric fat and the ipsilateral adrenal gland. The modern radical nephrectomy definition allows for adrenal-sparing if there is no clinical evidence of adrenal gland invasion or metastasis and it is surgically safe to do so. The evolution of indications for MI-RN reflects the evolution in surgical technique over time. Initially, LRN was reserved for small renal tumors $(<4 \mathrm{~cm})$. With increasing experience and confidence with the technique, LRN was adopted as the standard of care for larger renal tumors with good perioperative and oncological outcomes $(5,6)$.

Population-based data show a trend towards increased utilization of partial nephrectomy for renal masses over the last decade (7). In particular, data from the National Cancer Database demonstrated increased utilization of robotic surgery for small renal masses from $41 \%$ in 2010 to $63 \%$ in 2013 (8). Nephron-sparing surgery appears to have equivalent oncological outcomes for masses up to $7 \mathrm{~cm}$ while preserving renal function compared to radical nephrectomy in patients with a normal contralateral kidney (9-11). Thus, currently, MI-RN is the recommended standard of care for the curative treatment of large or central renal masses where a nephron-sparing surgery is not feasible (12). The use of a laparoscopic or robotic-assisted approach depends on availability, surgeon preference and shared patient/surgeon decision-making. Further, while nephron-sparing surgery has reduced the need for radical nephrectomy, the robotic platform has enabled expansion of the clinical indications for MI-RN including more advanced disease states, locally advanced renal tumors, cytoreductive nephrectomy (CN) in metastatic disease, $\mathrm{RN}$ with concurrent retroperitoneal lymphadenopathy and $\mathrm{RN}$ with concurrent inferior vena cava (IVC) tumor thrombectomy.

\section{LRN outcomes}

Numerous studies attest to the lower operative morbidity and improved perioperative outcomes with LRN compared to ORN, specifically reduced post-operative pain, analgesic requirements, estimated blood loss, need for transfusions, length of hospital stay and more rapid convalescence and return to daily activities (13-15). Further, there are no differences in longer term oncological efficacy between the two groups (16-20). Luo et al. reported 3-, 5-, and 7-year cancer-specific survival rates
$96.3 \%, 94.6 \%$, and $92.5 \%$, respectively, for LRN in 142 patients with a median follow-up of approximately 4 years (19), while Gill and colleagues demonstrated 10 -year overall, cancer specific and recurrence-free survival rates of $65 \%, 92 \%$ and $86 \%$ respectively with $\mathrm{LRN}$ after a median follow-up of $>11$ years (18). Hemal et al. showed no difference in 5-year survival data in their prospective comparison of LRN and ORN (20). Similarly, a study of 112 patients undergoing $\mathrm{RN}$ for clinical stage T2N0M0 renal tumors demonstrated similar 5-year recurrencefree, cancer-specific and overall survival between LRN and ORN: $93 \%$ vs. $91 \%(\mathrm{P}=0.9), 95 \%$ vs. $94 \%(\mathrm{P}=0.8)$ and $88 \%$ vs. $89 \%(\mathrm{P}=0.9)$, respectively $(20)$.

\section{LRN for locally advanced tumors}

LRN is also effective for selected patients with locally advanced renal tumors with longer term data establishing oncological equivalence $(20,21)$. A matched comparison of LRN $v s$. ORN in 179 patients with pT3N0M0 renal tumors without vena caval invasion demonstrated no difference in cancer-specific survival in the entire cohort $(\mathrm{P}=0.7)$ and in subgroups of patients with peri-renal fat invasion $(\mathrm{P}=0.9)$ or renal vein invasion $(\mathrm{P}=0.3)(21)$. In another study including $\mathrm{pT} 3$ or $\mathrm{pT} 4$ renal tumors, $\mathrm{MI}-\mathrm{RN}$ was associated with lower blood loss (277 vs. $1429 \mathrm{~mL}, \mathrm{P}<0.01$ ), lower blood transfusion $(4.7 \%$ vs. $45.5 \%, \mathrm{P}<0.01)$, and a shorter length of stay ( 3.5 vs. 5.7 days, $\mathrm{P}<0.01$ ) compared to ORN with no significant difference in overall survival at 3 years $(\mathrm{P}=0.8)(22)$.

\section{Retroperitoneoscopic radical nephrectomy}

While most MI-RN is performed transperitoneally, a retroperitoneoscopic approach may be considered in selected patients. The transperitoneal approach has the advantages of a wider working space and more easily identifiable anatomical landmarks. However, it also requires bowel mobilization and adhesiolysis in cases of previous transperitoneal abdominal surgery. The retroperitoneal approach, on the other hand, allows extraperitoneal dissection and direct access to the renal hilum while avoiding the need for bowel mobilization and adhesiolysis. Relative indications for a retroperitoneoscopic approach include a hostile surgical abdomen from multiple transperitoneal open surgical procedures, peritoneal dialysis, pregnancy and morbid obesity. In pregnancy, a retroperitoneoscopic surgery may minimize peritoneal 
and uterine irritation and the risk of preterm labor (23). In morbidly obese patients, the retroperitoneoscopic approach may simplify the procedure by avoiding the abdominal pannus and voluminous visceral fat encountered during transperitoneal RN (24). Limitations of this approach include the smaller working area in the retroperitoneal space, and reduced traction and instrument mobility. Typically a 3-port technique is used for retroperitoneoscopic LRN while 5 ports are used for robotic-assisted radical nephrectomy (RARN).

A few technical considerations are particularly important with the retroperitoneoscopic approach. Proper balloon dilation in the avascular plane between the psoas fascia posteriorly and Gerota's fascia anteriorly is imperative. A spherical or oval shape balloon dilator can be used. This step mobilizes the Gerota's fascia covering the kidney anteromedially and exposes important anatomical landmarks including the psoas muscle, the ipsilateral peritoneal reflection, the ureter, the IVC on the right side and the aortic pulsations on the left side. After balloon dilation, the renal hilum is readily accessible and thus the size of the renal mass or kidney is not a significant issue during the hilar dissection. Mobilization of the specimen along avascular planes is important to further develop and enlarge the retroperitoneal space as the dissection proceeds. The entire procedure can be completed without a peritoneal opening except for entrapment of large masses prior to extraction.

Several studies have demonstrated the feasibility, safety and longer-term oncological efficacy of retroperitoneoscopic LRN (25-27). Perioperative morbidity is comparable to transperitoneal LRN $(28,29)$ including in the morbidly obese patient (BMI $\left.>40 \mathrm{~kg} / \mathrm{m}^{2}\right)(24)$. While a retrospective comparative study suggested improved operation times, blood loss, and time to commencement of diet with retroperitoneal LRN (30), two randomized trials of retroperitoneoscopic vs. transperitoneal LRN have demonstrated equivalent perioperative morbidity, complications and pathological outcomes between the two approaches $(28,31)$.

\section{RARN}

Following the introduction of RARN in 2005, there have been several small single-arm and comparative series demonstrating the safety, feasibility and efficacy of this approach compared to standard LRN (32-35) in the Untied States. A study of MI-RN from the Johns Hopkins comparing 243 LRNs with 76 RARNs demonstrated equivalent operative time (136 vs. $139 \mathrm{~min}, \mathrm{P}=0.53$ ), intraoperative complications $(2.8 \%$ vs. $2.0 \%, \mathrm{P}=0.65)$, and length of stay ( 2 vs. 2 days, $\mathrm{P}=0.75$ ) (34). RARN cases were more likely to include lymph node dissection (LND) (12.6\% vs. $24.2 \%, \mathrm{P}=0.03)$ and had greater estimated blood loss (50 vs. $100 \mathrm{~mL}, \mathrm{P}=0.04)$. There were no statistically significant differences in the total hospital charges between the two groups ( $\$ 14,913$ vs. $\$ 16,265, \mathrm{P}=0.17)$. Jeong and colleagues published a population-based comparison of LRN vs. RARN from 2003 to 2015 with the primary outcome assessing utilization trends and the secondary outcome evaluating perioperative complications and the use of resources (36). The utilization of RARN increased from $1.5 \%$ in 2003 to $27.0 \%$ in 2015 . There were no differences in the rate of minor and major complications between the two groups. The RARN group had a higher proportion of patients with a prolonged operating time ( $>4$ hours) and higher mean 90-day direct hospital costs which was attributed to higher operating room and supply costs. Evaluating overall cost-benefit of RARN from direct hospital costs alone, however, is simplistic and overlooks several important factors (37). The technical complexity of radical nephrectomy depends on myriad patient, anatomic, and tumor factors (Table 1). Most of these factors were not considered in this paper's regression model. The authors found that from 2010 to 2015 , the total number of radical nephrectomies in the United States reduced by $22 \%$ from 4,100 to 3,194 cases annually. This reduction during a time of increased robotic utilization may be, in part, due to a higher rate of successful partial nephrectomies using the robotic platform. The same group used the Premier Healthcare Database to assess the rate of "unsuccessful" partial nephrectomy which was defined as intraoperative conversion from partial to radical nephrectomy comparing robotic, laparoscopic and open approaches (38). The robotic partial nephrectomy group had the lowest rate of conversion to radical nephrectomy (14\%) while laparoscopic partial nephrectomy had the highest conversion rate $(35 \%)$ which again reflects the benefits of the robotic platform over pure laparoscopy. Further, most centers that perform RARN already have one or more robotic systems installed for other procedures and there is no additional capital cost involved. Finally, robotic technology has significant implications for surgical education, training and assessment. Contemporary urological training in the United States and other countries facilitates greater exposure to robotic surgery compared to laparoscopy which may translate to greater levels of 
Table 1 Factors affecting complexity of radical nephrectomy

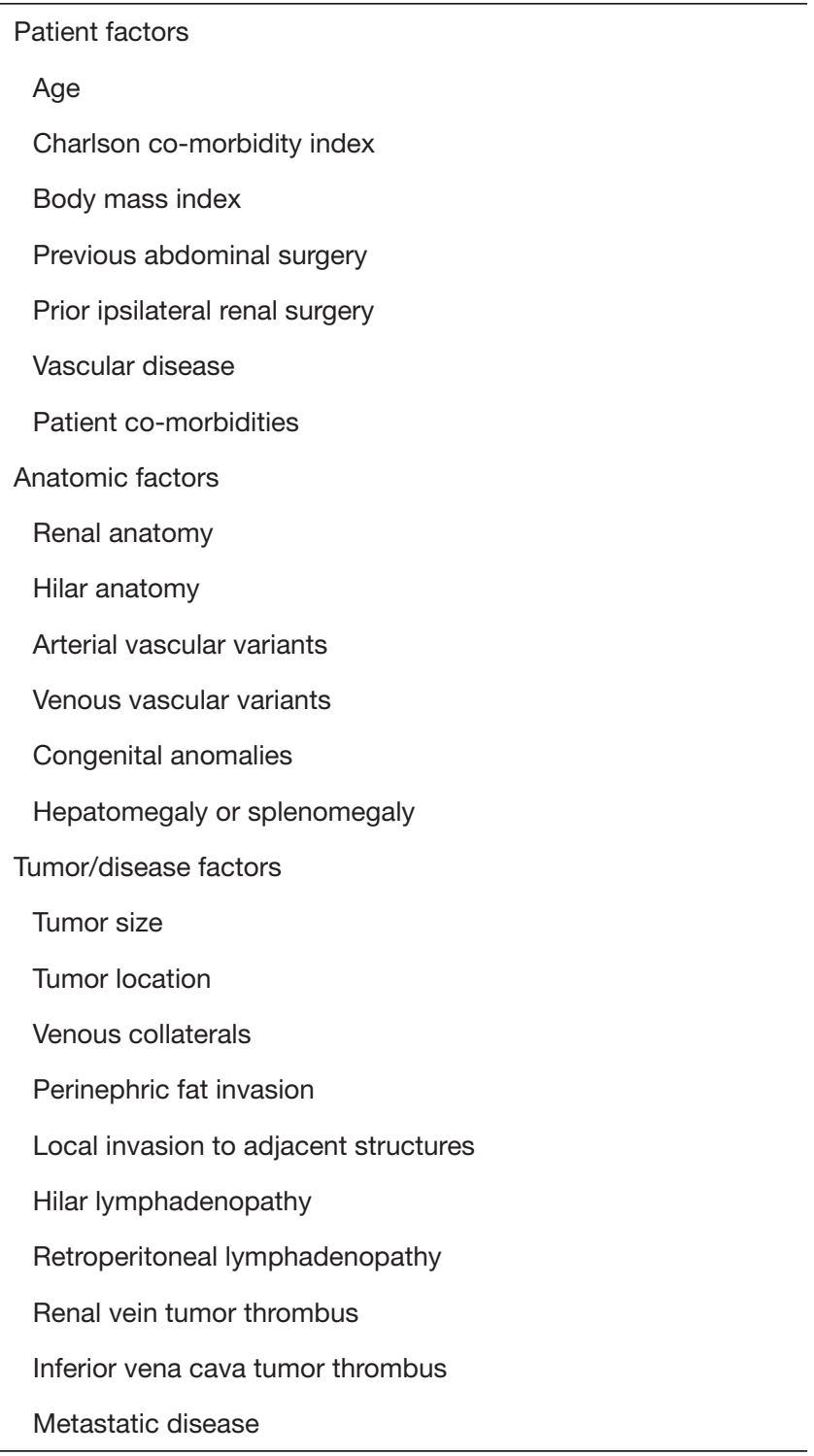

proficiency and expertise using the robotic platform. Robotic technology also allows objective assessment of technical skills in a way that is unparalleled in previous eras of surgical training (39).

The multi-institutional ROSULA Collaborative Group compared 404 RARN and 537 LRN cases for large renal masses ( $\geq \mathrm{cT} 2)$ from an international multi-institutional database (40). Over the 14-year study period from 2004 to 2017 , there was increased utilization of RARN with an annual increase of approximately $12 \%$ compared with a $5 \%$ annual decline in LRN. Analysis of baseline cohort characteristics and pathological findings confirmed that
RARN was being performed in a more advanced and surgically challenging patient cohort. RARN patients had higher BMI (27.6 vs. $\left.26.5 \mathrm{~kg} / \mathrm{m}^{2}, \mathrm{P}<0.01\right)$, and presented with more advanced disease state, specifically a higher histologic grade (high-grade: $49 \%$ vs. $30 \%, \mathrm{P}<0.01$ ), a higher pathologic stage (pT3-4: $53 \%$ vs. $24 \%, \mathrm{P}<0.01$ ), and higher rate of nodal disease (pN1: $5.4 \%$ vs. $1.9 \%$, $\mathrm{P}<0.01)$. There was no difference in estimated blood loss, intra-operative transfusions, overall complication rate, and major complication rate. Although RARN had longer operating times, it was also associated with shorter hospital stays $(\mathrm{P}<0.01)$. There was no difference in medium-term recurrence-free survival and overall survival between groups. This study, the largest multi-center comparison of RARN and LRN, highlighted three key findings in the contemporary era of MI-RN: (I) there is a trend of increasing use of RARN over LRN; (II) RARN is being performed for larger and more advanced renal tumors; and (III) RARN has equivalent perioperative morbidity despite its utilization in a more challenging surgical cohort.

Overall, the literature suggests that RARN is being performed in more challenging cases where LRN may not be technically feasible or may be too time consuming. In many cases the alternative is major open abdominal surgery, compared to which RARN consistently provides benefits of reduced blood loss, pain, opiate consumption, length of stay and overall recovery time. We believe robotic-assisted technology provides incremental clinical benefit compared to pure laparoscopy even in the event of a potential increase in cost.

\section{MI-RN with retroperitoneal LND}

LND is not routinely performed during radical nephrectomy for RCC. The European Organisation for Research and Treatment of Cancer (EORTC) phase III randomized trial demonstrated no significant benefit with LND compared to no LND in regards to progression-free survival, time to progression and overall survival in clinically localized RCC without regional lymphadenopathy (cN0M0 RCC) (41). This in part may be due to the low incidence of unsuspected lymph node metastasis in the LND arm (4.0\%) (41). Data from retrospective studies suggests that concurrent LND may be of oncological benefit in higher risk patients with pre-operative or intra-operative regional lymph node enlargement (cN1M0 RCC) (42). Schafhauser and colleagues' study of 1,035 patients found that more extensive LND was associated favorable long-term overall 
survival compared to no LND or limited sampling of nodes (43). Capitanio et al. evaluated 1,983 patients undergoing nephrectomy for RCC and found that the number of nodes removed with LND correlated with metastasis-free survival and cancer-specific survival in patients with bulky tumors ( $>10 \mathrm{~cm}$ in size), pathological stage $\mathrm{pT} 2 / \mathrm{pT} 3 \mathrm{c} / \mathrm{pT} 4$ tumors or tumors with sarcomatoid features (44). A recent systematic review and meta-analysis of LND in RCC showed that some higher risk patients with pN1M0 disease are able to achieve long-term oncological control after surgery with a 10 -year cancer-specific survival of $21-31 \%$ (45). This, of course, is in addition to the potential benefits of better pathological staging and prognostication in higher risk patients. Children and adolescents are another subset of patients that benefit from LND at initial surgery (46). They may be at higher risk of occult nodal involvement with up to $33 \%$ of children and adolescents with RCC harboring nodal metastasis (47). Clinically enlarged retroperitoneal nodes in the context of RCC represents a challenging surgical scenario, particularly given the potential for vascular injury and need for expedient control and suture repair of major vessels. Robotic-assisted surgery has enabled the adoption of minimally invasive retroperitoneal $\mathrm{LND}$ at $\mathrm{RN}(46,48,49)$. At our center, we have one of the largest experiences with extended retroperitoneal LND in cN1 RCC which can be performed safely with minimal morbidity.

\section{Minimally invasive cytoreductive radical nephrectomy}

Approximately $15 \%$ of renal cancers are metastatic at diagnosis (50). While systemic therapy is the cornerstone of contemporary treatment in metastatic RCC, CN may be considered in well-selected patients (51-53). The CARMENA (Cancer du Rein Metastatique Nephrectomie et Antiangiogéniques) randomized trial of $\mathrm{CN} v s$. no $\mathrm{CN}$ demonstrated no survival benefit to surgery in intermediate and poor-risk metastatic RCC (54), confirming previous publications dissuading the use of $\mathrm{CN}$ in poor-risk disease (55). Our experience reflects the notion that the patients most likely to benefit from $\mathrm{CN}$ are those with favorable-risk disease, limited metastatic burden, and those who have had good response to an initial trial of systemic therapy (55). The Immediate Surgery or Surgery After Sunitinib Malate in Treating Patients With Metastatic Kidney Cancer (SURTIME) randomized trial evaluated the timing of $\mathrm{CN}$ comparing early $\mathrm{CN}$ prior to systemic therapy with deferred $\mathrm{CN}$ after an initial period of systemic therapy, demonstrating a $43 \%$ relative reduction in overall mortality and improved median overall survival from 15 to 32 months with deferred CN (56). Furthermore, minimally invasive $\mathrm{CN}$ can further expedite post-operative convalescence and commencement of systemic therapy following surgery (57). Laparoscopic $\mathrm{CN}$ has been shown to be safe and feasible $(58,59)$. It has been associated with reduced morbidity and improved perioperative outcomes in several comparative series of laparoscopic vs. open $\mathrm{CN}$, specifically estimated blood loss, transfusion rate, number of transfusions, time to oral intake and hospital stay (60-64). Importantly, these studies also show that laparoscopic $\mathrm{CN}$ does not appear to delay and may in fact shorten the interval from nephrectomy to commencement of systemic therapy. More recently, a multi-institutional study of 120 patients from three high-volume centers between 2001 to 2013 demonstrated acceptable surgical morbidity and oncological outcomes in patients undergoing minimally invasive $\mathrm{CN}$, of which $3 \%$ were robotic and $97 \%$ were laparoscopic procedures (65). Minimally invasive $\mathrm{CN}$ was associated with an overall complication rate of $23 \%$, a major complication rate of $7 \%$, conversion rate of $3 \%$ and 3 -year survival of $35 \%$ (65). Currently, minimally invasive $\mathrm{CN}$ is the preferred surgical approach in most metastatic RCC patients being considered for cytoreductive surgery.

\section{Minimally invasive IVC tumor thrombectomy}

RCC with venous tumor thrombus extending to the IVC has an estimated prevalence of 4-10\% (66). Venous tumor thrombi (VTT) have traditionally been classified according to the cephalad extent of the thrombus into 5 levels: level 0 extending to the renal vein, level I extending into the IVC but $<2 \mathrm{~cm}$ above the renal vein, level II extending into the IVC $>2 \mathrm{~cm}$ above the renal vein (infra-hepatic), level III extending to the liver (intrahepatic), and level IV extending above the diaphragm (67). Patients with VTT have poor prognosis with non-operative management with an estimated 1-year survival of 29\% (68). Aggressive surgical management with complete resection of tumor thrombus is the only treatment option that offers the potential for cure in these patients $(69,70)$. Radical nephrectomy with IVC tumor thrombectomy is a technically and physically demanding procedure, and has traditionally been performed open surgically with significant associated risks of perioperative morbidity and mortality (71). Perioperative mortality rates range from $3.5-9.6 \%$ in 
large single-center and multi-institutional series (71-75). The International Renal Cell Carcinoma-Venous Thrombus Consortium (IRCCVTC) of 11 institutions around Europe and the United States evaluated 1,122 patients, observing a direct correlation between thrombus level and perioperative mortality: level I at 5.4\%, level II at 4.3\%, and level III at $19.4 \%(\mathrm{P}<0.001)(75)$.

Minimally invasive techniques for IVC tumor thrombectomy were initially developed in the laboratory setting with animal models $(76,77)$. This paved the way for the introduction of laparoscopic approaches to tumor thrombectomy, predominantly for level I-II thrombi (78-85). The procedure is technically demanding even in the hands of experienced laparoscopic surgeons. The uptake of laparoscopic IVC thrombectomy was hampered by various limitations including rigid instrumentation, restricted movements, transmitted physiological tremor, prolonged learning curve and more specifically difficulty in suture repair of the IVC and controlling major intraabdominal bleeding.

The introduction of robotic-assisted technology has enabled urologists to perform IVC thrombectomy in a minimally invasive manner with the potential to reduce perioperative morbidity including reduced blood loss and transfusions, as well as shorter operating times and length of hospital stay while overcoming the limitations of a purely laparoscopic approach $(86,87)$. There have been several successful reports demonstrating the safety and feasibility of a robotic-assisted approach to IVC tumor thrombectomy for level 0, I and II thrombi in experienced hands (86-95). Our preoperative preparation, port placement, and "IVC-first, kidney-last approach" to level II-III thrombi has been reported previously (93). Gu and colleagues reported reduced operating time, blood loss, transfusions, postoperative complications and hospital stay in patients undergoing robotic IVC thrombectomy compared to open surgery for level 1-2 thrombi in a matched comparative study of 31 robotic versus 31 open cases (96). Robotic techniques for vena cava control for intrahepatic thrombi were developed in cadavers $(97,98)$. The initial series of 16 robotic level 3 IVC tumor thrombectomy cases was reported in 2015 demonstrating safety and feasibility with appropriate patient selection and robotic experience (93). Other centers have reported similar results (99-103). Oneyear survival outcomes have been assessed demonstrating excellent oncological control (104). Preoperative planning is critical. Our preoperative practice routinely includes multidisciplinary consultation (with diagnostic radiology, interventional radiology, cardiology, cardiothoracic and hepatobiliary surgical teams for level 3 thrombi), 2D radiology line drawings and $3 \mathrm{D}$ CT reconstructions of the renal, vascular and tumor anatomy, preoperative angioinfarction of the tumor-bearing kidney, admission to hospital the day prior to surgery and arrangements for "realtime" intraoperative transesophageal echocardiography $(105,106)$.

The robotic IVC thrombectomy procedure continues to evolve and further technical advances have been described (107). The initial robotic-assisted level IV IVC thrombectomy was performed in 2017 (108). In appropriately selected patients, proximal caval occlusion can be achieved robotically for intrahepatic IVC tumor thrombi using a Coda LP or Fogarty intracaval balloon catheter (105). Robotic vena cavoscopy can be performed using an on-table flexible cytoscope to ensure complete removal of intrahepatic thrombi (107). The IVC can be repaired with robotic bovine pericardial patch cavoplasty (107). In patients with complete caval occlusion, robotic supra-renal cavectomy can be performed using an endoscopic stapler to divide the infrahepatic IVC.

\section{Future perspectives in MI-RN}

Nephron-sparing surgery has been playing an increasingly crucial role in the surgical management of renal cancer. Recent propensity-matched comparisons have demonstrated that robotic partial nephrectomy for large $(>7 \mathrm{~cm})$ clinical T2a masses has similar safety profile and 5-year oncological outcomes compared to MI-RN with the added benefit of renal function preservation and improved 5 -year freedom from stage 3 chronic kidney disease (109). Similar findings have been reported in the elderly population (110). With burgeoning expertise in complex robotic partial nephrectomy for large renal masses, the role of MI-RN for localized renal masses may become increasingly limited in the future. On the other hand, the utility of MI-RN is likely to encompass new and expanded indications due to the incremental clinical benefit provided by the robotic platform over pure laparoscopy. The excellent exposure provided by laparoscopy combined with the improved vision, magnification, dexterity and maneuverability of the robotic platform allows experienced surgeons to perform more complex and technical demanding procedures in a minimally invasive manner. The widespread availability of robotic technology is likely to drive utilization of robotic radical nephrectomy for these complex cases 
including locally advanced renal cancer invading adjacent structures, cytoreductive surgery in metastatic renal cancer, retroperitoneal LND for bulky regional lymphadenopathy, and tumor thrombectomy for venous tumor thrombus extending to the vena cava. Increased exposure and surgical experience with difficult retroperitoneal surgical anatomy through the robotic platform will expedite the urological surgeon's learning curve for these difficult cases by integration and consolidation of previously acquired technical and cognitive skills.

\section{Conclusions}

MI-RN has undergone significant evolution over the last 10-20 years and is currently the standard of care for renal masses not suitable for nephron-sparing surgery. LRN can be performed when technically feasible. Increasingly, the robotic platform has allowed patients with more advanced disease states requiring more technically demanding surgery to benefit from minimally invasive surgery including $\mathrm{CN}$, concurrent retroperitoneal lymphadenectomy and vena cava tumor thrombectomy.

\section{Acknowledgments}

Funding: None.

\section{Footnote}

Provenance and Peer Review: This article was commissioned by the Guest Editor (Shomik Sengupta) for the series "Surgery for Urologic Cancers" published in Translational Andrology and Urology. The article has undergone external peer review.

Conflicts of Interest: Both authors have completed the ICMJE uniform disclosure form (available at http://dx.doi. org/10.21037/tau-2019-suc-16). The series "Surgery for Urologic Cancers" was commissioned by the editorial office without any funding or sponsorship. The authors have no other conflicts of interest to declare.

Ethical Statement: The authors are accountable for all aspects of the work in ensuring that questions related to the accuracy or integrity of any part of the work are appropriately investigated and resolved.

Open Access Statement: This is an Open Access article distributed in accordance with the Creative Commons Attribution-NonCommercial-NoDerivs 4.0 International License (CC BY-NC-ND 4.0), which permits the noncommercial replication and distribution of the article with the strict proviso that no changes or edits are made and the original work is properly cited (including links to both the formal publication through the relevant DOI and the license). See: https://creativecommons.org/licenses/by-nc-nd/4.0/.

\section{References}

1. Siegel RL, Miller KD, Jemal A. Cancer statistics, 2020. CA Cancer J Clin 2020;70:7-30.

2. Robson CJ. Radical nephrectomy for renal cell carcinoma. J Urol 1963;89:37-42.

3. Robson CJ, Churchill BM, Anderson W. The results of radical nephrectomy for renal cell carcinoma. J Urol 1969;101:297-301.

4. Clayman RV, Kavoussi LR, Soper NJ, et al. Laparoscopic nephrectomy: initial case report. J Urol 1991;146:278-82.

5. Conley SP, Humphreys MR, Desai PJ, et al. Laparoscopic radical nephrectomy for very large renal tumors $(>$ or $=10$ $\mathrm{cm})$ : is there a size limit? J Endourol 2009;23:57-61.

6. Steinberg AP, Finelli A, Desai MM, et al. Laparoscopic radical nephrectomy for large (greater than $7 \mathrm{~cm}, \mathrm{~T} 2$ ) renal tumors. J Urol 2004;172:2172-6.

7. Liss MA, Wang S, Palazzi K, et al. Evaluation of national trends in the utilization of partial nephrectomy in relation to the publication of the American Urologic Association guidelines for the management of clinical T1 renal masses. BMC Urol 2014;14:101.

8. Alameddine M, Koru-Sengul T, Moore KJ, et al. Trends in Utilization of Robotic and Open Partial Nephrectomy for Management of cT1 Renal Masses. Eur Urol Focus 2019;5:482-7.

9. Weight CJ, Larson BT, Gao T, et al. Elective Partial Nephrectomy in Patients With Clinical T1b Renal Tumors Is Associated With Improved Overall Survival. Urology 2010;76:631-7.

10. Weight CJ, Lieser G, Larson BT, et al. Partial Nephrectomy Is Associated with Improved Overall Survival Compared to Radical Nephrectomy in Patients with Unanticipated Benign Renal Tumours. Eur Urol 2010;58:293-8.

11. Leibovich BC, Blute ML, Cheville JC, et al. Nephron Sparing Surgery for Appropriately Selected Renal Cell Carcinoma Between 4 and $7 \mathrm{Cm}$ Results in Outcome Similar to Radical Nephrectomy. J Urol 2004;171:1066-70. 
12. Motzer RJ, Jonasch E, Agarwal N, et al. Kidney Cancer, Version 2.2017, NCCN Clinical Practice Guidelines in Oncology. J Natl Compr Canc Netw 2017;15:804-34.

13. Gill IS, Meraney AM, Schweizer DK, et al. Laparoscopic radical nephrectomy in 100 patients. Cancer 2001;92:1843-55.

14. Burgess NA, Koo BC, Calvert RC, et al. Randomized Trial of Laparoscopic v Open Nephrectomy. J Endourol 2007;21:610-3.

15. Liu G, Ma Y, Wang S, et al. Laparoscopic Versus Open Radical Nephrectomy for Renal Cell Carcinoma: a Systematic Review and Meta-Analysis. Transl Oncol 2017;10:501-10.

16. Ono Y, Kinukawa T, Hattori R, et al. Laparoscopic radical nephrectomy for renal cell carcinoma: a five-year experience. Urology 1999;53:280-6.

17. Dunn MD, Portis AJ, Shalhav AL, et al. Laparoscopic versus open radical nephrectomy: a 9-year experience. J Urol 2000;164:1153-9.

18. Berger A, Brandina R, Atalla MA, et al. Laparoscopic radical nephrectomy for renal cell carcinoma: oncological outcomes at 10 years or more. J Urol 2009;182:2172-6.

19. Luo JH, Zhou FJ, Xie D, et al. Analysis of long-term survival in patients with localized renal cell carcinoma: laparoscopic versus open radical nephrectomy. World J Urol 2010;28:289-93.

20. Hemal AK, Kumar A, Kumar R, et al. Laparoscopic Versus Open Radical Nephrectomy for Large Renal Tumors: A Long-Term Prospective Comparison. J Urol 2007;177:862-6.

21. Bensalah K, Salomon L, Lang H, et al. Survival of patients with nonmetastatic pT3 renal tumours: a matched comparison of laparoscopic vs open radical nephrectomy. BJU Int 2009; 104:1714-7.

22. Bragayrac LA, Abbotoy D, Attwood K, et al. Outcomes of Minimal Invasive vs Open Radical Nephrectomy for the Treatment of Locally Advanced Renal-Cell Carcinoma. J Endourol 2016;30:871-6.

23. Yin L, Zhang D, Teng J, et al. Retroperitoneal laparoscopic radical nephrectomy for renal cell carcinoma during pregnancy. Urol Int 2013;90:487-9.

24. Berglund RK, Gill IS, Babineau D, et al. A prospective comparison of transperitoneal and retroperitoneal laparoscopic nephrectomy in the extremely obese patient. BJU Int 2007;99:871-4.

25. Gill IS, Schweizer D, Hobart MG, et al. Retroperitoneal laparoscopic radical nephrectomy. J Urol 2000:1665-70.

26. Abbou CC, Cicco A, Gasman D, et al. Retroperitoneal laparoscopic versus open radical nephrectomy. J Urol 1999;161:1776-80.

27. Larré S, Kanso C, De La Taille A, et al. Retroperitoneal laparoscopic radical nephrectomy: intermediate oncological results. World J Urol 2008;26:611-5.

28. Desai MM, Strzempkowski B, Matin SF, et al. Prospective randomized comparison of transperitoneal versus retroperitoneal laparoscopic radical nephrectomy. J Urol 2005;173:38-41.

29. Nadler RB, Loeb S, Clemens JQ, et al. A prospective study of laparoscopic radical nephrectomy for T1 tumors--is transperitoneal, retroperitoneal or hand assisted the best approach? J Urol 2006;175:1230-3; discussion 1234.

30. Kim HY, Lee DS, Yoo JM, et al. Retroperitoneal Laparoscopic Radical Nephrectomy for Large $(>7 \mathrm{~cm})$ Solid Renal Tumors: Comparison of Perioperative Outcomes with the Transperitoneal Approach. J Laparoendosc Adv Surg Tech A 2017;27:393-7.

31. Nambirajan T, Jeschke S, Al-Zahrani H, et al. Prospective, randomized controlled study: transperitoneal laparoscopic versus retroperitoneoscopic radical nephrectomy. Urology 2004;64:919-24.

32. Klingler DW, Hemstreet GP, Balaji KC. Feasibility of robotic radical nephrectomy-initial results of singleinstitution pilot study. Urology 2005;65:1086-9.

33. Hemal AK, Kumar A. A prospective comparison of laparoscopic and robotic radical nephrectomy for T12N0M0 renal cell carcinoma. World J Urol 2009;27:89-94.

34. Helmers MR, Ball MW, Gorin MA, et al. Robotic versus laparoscopic radical nephrectomy: comparative analysis and cost considerations. Can J Urol 2016;23:8435-40.

35. Nazemi T, Galich A, Sterrett S, et al. Radical nephrectomy performed by open, laparoscopy with or without handassistance or robotic methods by the same surgeon produces comparable perioperative results. Int Braz J Urol 2006;32:15-22.

36. Jeong IG, Khandwala YS, Kim JH, et al. Association of Robotic-Assisted vs Laparoscopic Radical Nephrectomy With Perioperative Outcomes and Health Care Costs, 2003 to 2015. JAMA 2017;318:1561.

37. Cacciamani GE, Desai MM, Gill IS. A Larger Prospective Study is Needed When Judging Robotic Radical Nephrectomy. Eur Urol 2018;74:123-4.

38. Khandwala YS, Jeong IG, Kim JH, et al. The incidence of unsuccessful partial nephrectomy within the United States: A nationwide population-based analysis from 2003 to 2015. Urol Oncol 2017;35:672.e7-13.

39. Chen J, Cheng N, Cacciamani G, et al. Objective 
Assessment of Robotic Surgical Technical Skill: A

Systematic Review. J Urol 2019;201:461-9.

40. Anele UA, Marchioni M, Yang B, et al. Robotic versus laparoscopic radical nephrectomy: a large multiinstitutional analysis (ROSULA Collaborative Group). World J Urol 2019;37:2439-50.

41. Blom JH, van Poppel H, Marechal JM, et al. Radical nephrectomy with and without lymph-node dissection: final results of European Organization for Research and Treatment of Cancer (EORTC) randomized phase 3 trial 30881. Eur Urol 2009;55:28-34.

42. Motzer RJ, Jonasch E, Michaelson MD, et al. NCCN Guidelines Insights: Kidney Cancer, Version 2.2020. J Natl Compr Canc Netw 2019;17:1278-85.

43. Schafhauser W, Ebert A, Brod J, et al. Lymph node involvement in renal cell carcinoma and survival chance by systematic lymphadenectomy. Anticancer Res 1999;19:1573-8.

44. Capitanio U, Suardi N, Matloob R, et al. Extent of lymph node dissection at nephrectomy affects cancerspecific survival and metastatic progression in specific subcategories of patients with renal cell carcinoma (RCC). BJU Int 2014;114:210-5.

45. Bhindi B, Wallis CJD, Boorjian SA, et al. The role of lymph node dissection in the management of renal cell carcinoma: a systematic review and meta-analysis. BJU Int 2018;121:684-98.

46. Cost NG, Geller JI, DeFoor WR Jr, et al. A roboticassisted laparoscopic approach for pediatric renal cell carcinoma allows for both nephron-sparing surgery and extended lymph node dissection. J Pediatr Surg 2012;47:1946-50.

47. Sausville JE, Hernandez DJ, Argani P, et al. Pediatric renal cell carcinoma. J Pediatr Urol 2009;5:308-14.

48. Abaza R, Lowe G. Feasibility and adequacy of robotassisted lymphadenectomy for renal-cell carcinoma. J Endourol 2011;25:1155-9.

49. Simmons MN, Kaouk J, Gill IS, et al. Laparoscopic radical nephrectomy with hilar lymph node dissection in patients with advanced renal cell carcinoma. Urology 2007;70:43-6.

50. Siegel RL, Miller KD, Jemal A. Cancer statistics, 2019. CA Cancer J Clin 2019;69:7-34.

51. Bhindi B, Abel EJ, Albiges L, et al. Systematic Review of the Role of Cytoreductive Nephrectomy in the Targeted Therapy Era and Beyond: An Individualized Approach to Metastatic Renal Cell Carcinoma. Eur Urol 2019;75:111-28.

52. Bhindi B, Habermann EB, Mason RJ, et al. Comparative
Survival following Initial Cytoreductive Nephrectomy versus Initial Targeted Therapy for Metastatic Renal Cell Carcinoma. J Urol 2018;200:528-34.

53. García-Perdomo HA, Zapata-Copete JA, CastilloCobaleda DF. Role of cytoreductive nephrectomy in the targeted therapy era: A systematic review and metaanalysis. Investig Clin Urol 2018;59:2-9.

54. Méjean A, Ravaud A, Thezenas S, et al. Sunitinib Alone or after Nephrectomy in Metastatic Renal-Cell Carcinoma. N Engl J Med 2018;379:417-27.

55. Heng DY, Wells JC, Rini BI, et al. Cytoreductive nephrectomy in patients with synchronous metastases from renal cell carcinoma: results from the International Metastatic Renal Cell Carcinoma Database Consortium. Eur Urol 2014;66:704-10.

56. Bex A, Mulders P, Jewett $M$, et al. Comparison of Immediate vs Deferred Cytoreductive Nephrectomy in Patients With Synchronous Metastatic Renal Cell Carcinoma Receiving Sunitinib: The SURTIME Randomized Clinical Trial. JAMA Oncol 2019;5:164-70.

57. Pindoria N, Raison N, Blecher G, et al. Cytoreductive nephrectomy in the era of targeted therapies: a review. BJU Int 2017;120:320-8.

58. Finelli A, Kaouk JH, Fergany AF, et al. Laparoscopic cytoreductive nephrectomy for metastatic renal cell carcinoma. BJU Int 2004;94:291-4.

59. Blick C, Bott S, Muneer A, et al. Laparoscopic cytoreductive nephrectomy: a three-center retrospective analysis. J Endourol 2010;24:1451-5.

60. Eisenberg MS, Meng MV, Master VA, et al. Laparoscopic versus open cytoreductive nephrectomy in advanced renalcell carcinoma. J Endourol 2006;20:504-8.

61. Ganeshappa A, Sundaram C, Lerner MA, et al. Role of the laparoscopic approach to cytoreductive nephrectomy in metastatic renal-cell carcinoma: does size matter? J Endourol 2010;24:1289-92.

62. Matin SF, Madsen LT, Wood CG. Laparoscopic cytoreductive nephrectomy: the M. D. Anderson Cancer Center experience. Urology 2006;68:528-32.

63. Rabets JC, Kaouk J, Fergany A, et al. Laparoscopic versus open cytoreductive nephrectomy for metastatic renal cell carcinoma. Urology 2004;64:930-4.

64. Walther MM, Lyne JC, Libutti SK, et al. Laparoscopic cytoreductive nephrectomy as preparation for administration of systemic interleukin-2 in the treatment of metastatic renal cell carcinoma: a pilot study. Urology 1999;53:496-501.

65. Nunez Bragayrac L, Hoffmeyer J, Abbotoy D, et al. 
Minimally invasive cytoreductive nephrectomy: a multiinstitutional experience. World J Urol 2016;34:1651-6.

66. Marshall FF, Dietrick DD, Baumgartner WA, et al. Surgical Management of Renal Cell Carcinoma with Intracaval Neoplastic Extension Above the Hepatic Veins. J Urol 1988;139:1166-72.

67. Neves RJ, Zincke H. Surgical Treatment of Renal Cancer with Vena Cava Extension. Br J Urol 1987;59:390-5.

68. Reese AC, Whitson JM, Meng MV. Natural history of untreated renal cell carcinoma with venous tumor thrombus. Urol Oncol 2013;31:1305-9.

69. Skinner DG, Pfister RF, Colvin R. Extension of Renal Cell Carcinoma into the Vena Cava: The Rationale for Aggressive Surgical Management. J Urol 1972;107:711-6.

70. Skinner DG, Vermillion CD, Colvin RB. The surgical management of renal cell carcinoma. J Urol 1972;107:705-10.

71. Blute ML, Leibovich BC, Lohse CM, et al. The Mayo Clinic experience with surgical management, complications and outcome for patients with renal cell carcinoma and venous tumour thrombus. BJU Int 2004;94:33-41.

72. Staehler G, Brkovic D. The role of radical surgery for renal cell carcinoma with extension into the vena cava. J Urol 2000;163:1671-5.

73. Ciancio G, Manoharan M, Katkoori D, et al. Long-term Survival in Patients Undergoing Radical Nephrectomy and Inferior Vena Cava Thrombectomy: Single-Center Experience. Eur Urol 2010;57:667-72.

74. Wagner B, Patard JJ, Mejean A, et al. Prognostic value of renal vein and inferior vena cava involvement in renal cell carcinoma. Eur Urol 2009;55:452-9.

75. Martínez-Salamanca JI, Huang WC, Millán I, et al. Prognostic Impact of the 2009 UICC/AJCC TNM Staging System for Renal Cell Carcinoma with Venous Extension. Eur Urol 2011;59:120-7.

76. Meraney AM, Gill IS, Desai MM, et al. Laparoscopic Inferior Vena Cava and Right Atrial Thrombectomy Utilizing Deep Hypothermic Circulatory Arrest. J Endourol 2003;17:275-82.

77. Fergany AF, Gill IS, Schweizer DK, et al. Laparoscopic Radical Nephrectomy With Level II Vena Caval Thrombectomy: Survival Porcine Study. J Urol 2002;168:2629-31.

78. Desai MM, Gill IS, Ramani AP, et al. Laparoscopic Radical Nephrectomy For Cancer With Level I Renal Vein Involvement. J Urol 2003;169:487-91.

79. Disanto V, Pansadoro V, Portoghese F, et al. Retroperitoneal Laparoscopic Radical Nephrectomy for Renal Cell Carcinoma with Infrahepatic Vena Caval Thrombus. Eur Urol 2005;47:352-6.

80. Słojewski M, Gołąb A, Petrasz P, et al. Laparoscopic Radical Nephrectomy for T3B Tumor*. J Laparoendosc Adv Surg Tech A 2010;20:47-9.

81. Martin GL, Castle EP, Martin AD, et al. Outcomes of Laparoscopic Radical Nephrectomy in the Setting of Vena Caval and Renal Vein Thrombus: Seven-Year Experience. J Endourol 2008;22:1681-5.

82. Wang M, Ping H, Niu Y, et al. Pure conventional laparoscopic radical nephrectomy with level II vena cava tumor thrombectomy. Int Braz J Urol 2014;40:266-73.

83. Romero FR, Muntener M, Bagga HS, et al. Pure laparoscopic radical nephrectomy with level II vena caval thrombectomy. Urology 2006;68:1112-4.

84. Bansal RK, Tu HYV, Drachenberg D, et al. Laparoscopic Management of Advanced Renal Cell Carcinoma With Renal Vein and Inferior Vena Cava Thrombus. Urology 2014;83:812-6.

85. Hoang AN, Vaporcyian AA, Matin SF. LaparoscopyAssisted Radical Nephrectomy with Inferior Vena Caval Thrombectomy for Level II to III Tumor Thrombus: A Single-Institution Experience and Review of the Literature. J Endourol 2010;24:1005-12.

86. Lee JY, Mucksavage P. Robotic Radical Nephrectomy with Vena Caval Tumor Thrombectomy: Experience of Novice Robotic Surgeons. Korean J Urol 2012;53:879.

87. Abaza R. Initial series of robotic radical nephrectomy with vena caval tumor thrombectomy. Eur Urol 2011;59:652-6.

88. Satkunasivam R, Kim AE, Desai M, et al. Radical Prostatectomy or External Beam Radiation Therapy vs No Local Therapy for Survival Benefit in Metastatic Prostate Cancer: A SEER-Medicare Analysis. J Urol 2015;194:378-85.

89. Sun Y, de Castro Abreu AL, Gill IS. Robotic inferior vena cava thrombus surgery: novel strategies. Curr Opin Urol 2014;24:140-7.

90. Gu L, Ma X, Gao Y, et al. Robotic versus Open Level I-II Inferior Vena Cava Thrombectomy: A Matched Group Comparative Analysis. J Urol 2017;198:1241-6.

91. Wang B, Li H, Ma X, et al. Robot-assisted Laparoscopic Inferior Vena Cava Thrombectomy: Different Sides Require Different Techniques. Eur Urol 2016;69:1112-9.

92. Bratslavsky G, Cheng JS. Robotic-assisted Radical Nephrectomy With Retrohepatic Vena Caval Tumor Thrombectomy (Level III) Combined With Extended Retroperitoneal Lymph Node Dissection. Urology 2015;86:1235-40. 
93. Gill IS, Metcalfe C, Abreu A, et al. Robotic Level III Inferior Vena Cava Tumor Thrombectomy: Initial Series. J Urol 2015;194:929-38.

94. Estébanez Zarranz J, Belloso Loidi J, Gutierrez Garcia MA, et al. Radical robot-assisted laparoscopic nephrectomy with thrombectomy in the vena cava. Actas Urol Esp 2018;42:538-41.

95. Fan Y, Li H, Zhang X, et al. Robotic Radical Nephrectomy and Thrombectomy for Left Renal Cell Carcinoma with Renal Vein Tumor Thrombus: Superior Mesenteric Artery as an Important Strategic Dividing Landmark. J Endourol 2019;33:557-63.

96. Gu L, Ma X, Gao Y, et al. Robotic versus Open Level I-II Inferior Vena Cava Thrombectomy: A Matched Group Comparative Analysis. J Urol 2017;198:1241-6.

97. de Castro Abreu AL, Chopra S, Azhar RA, et al. Robotic Transabdominal Control of the Suprahepatic, Infradiaphragmatic Vena Cava to Enable Level 3 Caval Tumor Thrombectomy: Pilot Study in a Perfused-Cadaver Model. J Endourol 2015;29:1177-81.

98. Sood A, Jeong W, Barod R, et al. Robot-assisted hepatic mobilization and control of suprahepatic infradiaphragmatic inferior vena cava for level 3 vena caval thrombectomy: An IDEAL stage 0 study. J Surg Oncol 2015;112:741-5.

99. Wang B, Huang Q, Liu K, et al. Robot-assisted Level IIIIV Inferior Vena Cava Thrombectomy: Initial Series with Step-by-step Procedures and 1-yr Outcomes. Eur Urol 2020;78:77-86.

100. Wang B, Li H, Huang Q, et al. Robot-assisted Retrohepatic Inferior Vena Cava Thrombectomy: First or Second Porta Hepatis as an Important Boundary Landmark. Eur Urol 2018;74:512-20.

101.Nelson RJ, Maurice MJ, Kaouk JH. Robotic Radical Left Nephrectomy With Inferior Vena Cava Level III
Thrombectomy. Urology 2017;107:269.

102. Ramirez D, Maurice MJ, Cohen B, et al. Robotic Level III IVC Tumor Thrombectomy: Duplicating the Open Approach. Urology 2016;90:204-7.

103. Abaza R, Shabsigh A, Castle E, et al. Multi-Institutional Experience with Robotic Nephrectomy with Inferior Vena Cava Tumor Thrombectomy. J Urol 2016;195:865-71.

104. Chopra S, Simone G, Metcalfe C, et al. Robot-assisted Level II-III Inferior Vena Cava Tumor Thrombectomy: Step-by-Step Technique and 1-Year Outcomes. Eur Urol 2017;72:267-74.

105.Ashrafi A, Rajarubendra N, Nguyen H, et al. V06-02 robotic-assisted inferior vena cava tumor thrombectomy with intracaval balloon occlusion: a step-by-step technique. J Urol 2018;199:e661.

106. Essandoh M, Tang J, Essandoh G, et al. Transesophageal Echocardiography Guidance for Robot-assisted Level III Inferior Vena Cava Tumor Thrombectomy: A Novel Approach to Intraoperative Care. J Cardiothorac Vasc Anesth 2018;32:2623-7.

107. Kundavaram C, Abreu AL, Chopra S, et al. Advances in Robotic Vena Cava Tumor Thrombectomy: Intracaval Balloon Occlusion, Patch Grafting, and Vena Cavoscopy. Eur Urol 2016;70:884-90.

108. Ahmadi N, Cunningham M, Duddalwar V, et al. V0710 robotic assisted level iv inferior vena cava tumor thrombectomy. J Urol 2018;199:e744.

109. Contents/Inhalt/Table Des Matières. Canadian Biographical Index/Index Biographique Canadien/ Kanadischer Biographischer Index: De Gruyter Saur.

110. Veccia A, Dell'oglio P, Antonelli A, et al. Robotic partial nephrectomy versus radical nephrectomy in elderly patients with large renal masses. Minerva Urol Nefrol 2020;72:99-108.
Cite this article as: Ashrafi AN, Gill IS. Minimally invasive radical nephrectomy: a contemporary review. Transl Androl Urol 2020;9(6):3112-3122. doi: 10.21037/tau-2019-suc-16 